\title{
A Cross-Disciplinary Entrepreneurship Commercialization Process Model: Learning In Action
}

\author{
R. Wilburn Clouse \\ The Clouse-Elrod Foundation, Inc. \\ Vanderbilt University \\ Middle Tennessee State University \\ Stacy Wilson
Western Kentucky University \\ Ron Rizzo \\ Western Kentucky University
}

This paper will discuss how a multi-disciplinary team of engineering professors, business professors, entrepreneurs and students designed, developed and commercialized a new product related to an underwater submersible vehicle ...underwater Robot.

A new technology has been designed, developed and prototyped to aid in underwater exploration. The technology developed is a portable, remotely controlled submersible vehicle device capable of capturing high-quality images in depths up to 50 feet. The uniqueness of the new technology is that the device is significantly less expensive, more portable, and easier to deploy than other submersible vehicles on the market.

The paper will discuss product design, prototype development, competitive analysis, new market development, marketing strategies, cost analysis, and commercialization. Discussions will center on different cross disciplinary fields of study, such as electrical engineering, civil engineering, manufacturing, market analysis, entrepreneurship and commercialization. The paper will demonstrate the collaboration that occurred between these fields to form a truly interdisciplinary entrepreneurship venture. (Clouse, R. W. Aniello, J., Biernacki, J. 2003).

The paper suggests a paradigm change in curricula developed from around subject oriented learning and offers a model of integrated learning beginning with looking at the end product and developing a process and product that can be applied to the open market place.... authentic learning. (Creed, C. J., Suuberg, E. M. \& Crawford, G. P. 2002; Clouse, R. W. (1994). 
This project is an extension of the "Learning in Action" process developed by $R$ Wilburn Clouse and Terry Goodin at Vanderbilt University and adapted to include projects from other universities including this product from Western Kentucky University's electrical engineering department and the Center for Innovation and Entrepreneurship. (At the time of development of this project....R. Wilburn Clouse was the Executive Director of the WKU Center for Innovation and Entrepreneurship and Stacey Wilson was professor of Electrical Engineering). These two Professor co-directed the grant that developed this project. (Clouse, R. W., Goodin, T., Aniello, J. 2016).

A brief discussion of the Learning in Action concept is discussed below followed by the design, development and commercialization of the underwater robot. These discussions illustrate the unconventional thinking that permeated this project development.

\section{INTRODUCTION}

\section{Learning in Action! (LIA)}

We have developed a series of experiences that teach students to expand their thinking to be outside of "right or wrong answers" and linear thinking. We want students to learn to deal with chaos, uncertainty and to see new opportunities that come from a changing world. But yet, most of our formal educational systems teach students how to work and live in a stable and structured organizational world. Most curricular teaches structure, order, linear thinking and certainty, while the world is filled with chaos, ambiguity and uncertainty. Thus we have developed a learning environment to include new idea development, creativity, humor and entrepreneurship as a way of thinking about life in the 21 century.

Learning in Action! is a process connecting learning with the framework of the learner. It is a holistic approach to the learning process involving the whole-part-whole teaching strategies that connects the learning to live cases written across several different disciplines to develop an authentic learning experience. Our process is designed to be a creative force to help students see new and different ventures in life and to help the United States regain world recognition and redevelop a value system of business ethics and respect for life and the world environment. We want students to experience the power to think and to use this thinking power to build bridges across disciplines, across learning environments and across cultures. We want our students to develop the future, not follow the past. We have placed this process in the total framework of what we call Learning in Action!, to cause the application of knowledge, which is the ultimate reason for learning - thus creating Knowledge in Action! (Clouse, R. W., \& Goodin, T.L. 2001a; Clouse, R. W., Goodin, T. L. 2008).

This Remotely Operated Submersible, underwater robot, is a further extension of our work related to Learning in Action and was a great experience in developing a cross disciplinary Entrepreneurial Spirit project. (Clouse, R. W., Goodin, T. L. 2001b).

\section{Technical Design}

The objective of the new technology described in this paper is to commercialize a remotely controlled submersible device that has been designed, developed, and prototyped to aid in underwater exploration. The alpha prototype of this device was developed for a search and rescue team. The beta prototype was designed and tested to be smaller, less expensive, and more portable than the initial prototype. The basic system and each prototype will be described below followed by a discussion of the project statement of work.

\section{Basic System}

The submersible vehicle system is composed of two subsystems; a vehicle and controller; as shown in Figure 1 below. The controller and vehicle are connected via tether to relay power and control information between the controller and the vehicle. Each subsystem has fundamental components which are common to both prototypes also shown in the figure. 
FIGURE 1

BASIC SYSTEM BLOCK DIAGRAM

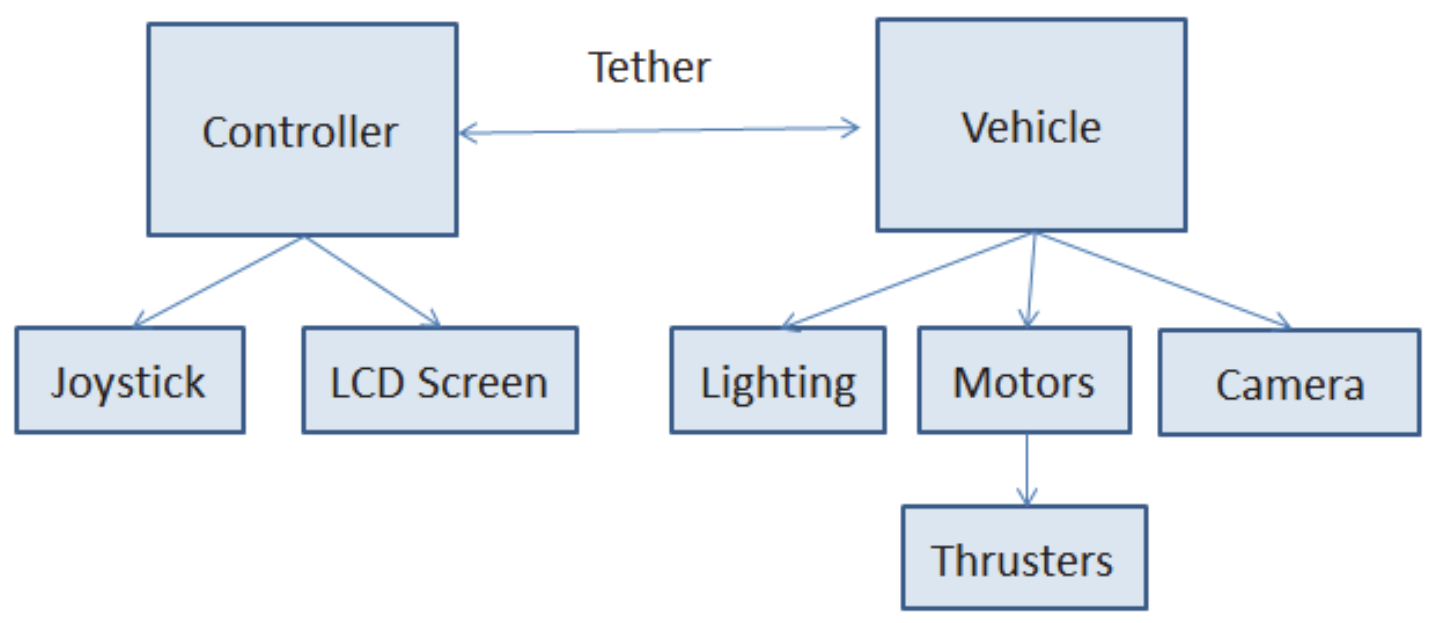

Alpha Prototype (ROS) Development

Search and rescue operations are often dangerous and difficult for divers. Several years ago, the Western Kentucky University (WKU) Department of Engineering was approached by Warren County Search and Rescue (WCSR) to develop a device that could aid in underwater searches. The search and rescue team owned an outer shell that they wished to be developed into a submersible vehicle device.

WKU Department of Engineering staff and students created the Remotely Controlled Submersible (ROS) vehicle, shown below in Figures 2 and 3. This device was successfully tested in a variety of situations including the Preston Center pool shown but also in outdoor search locations. The ROS device has been used consistently each summer since its' creation to aid the WCSR team in normal operations.

\section{FIGURE 2 \\ SUBMERSIBLE ROBOT, VIEW 1}

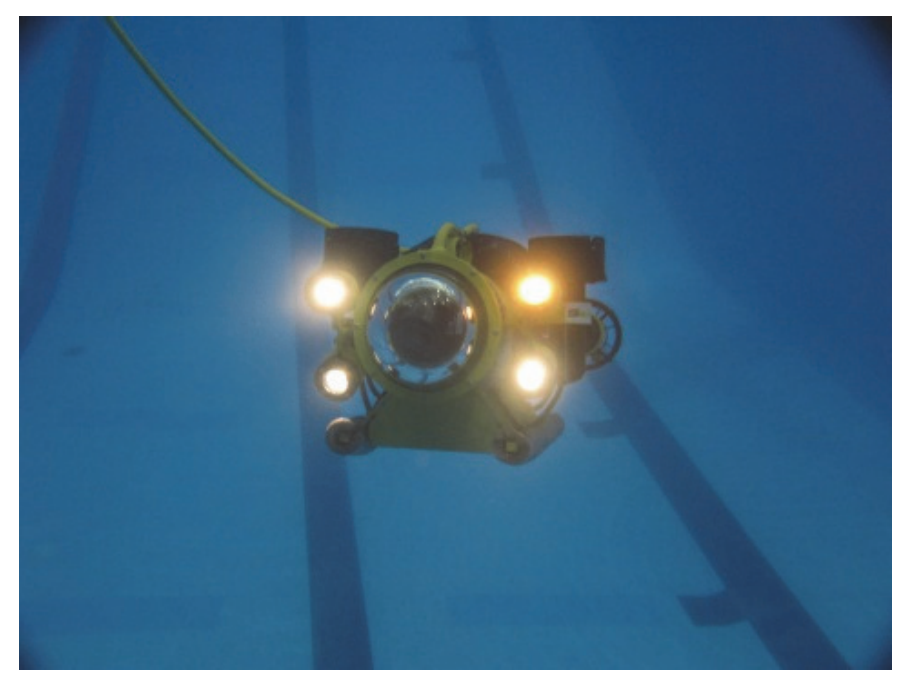


FIGURE 3

SUBMERSIBLE ROBOT, VIEW 2

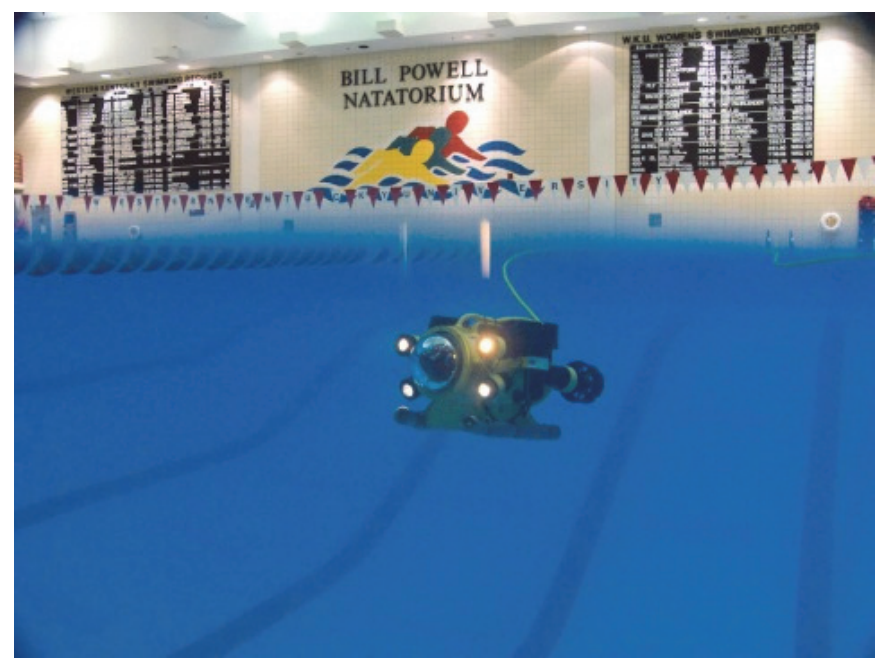

The robot was connected by tether to a control box that contained a video camera which allowed the user to have a visual of the underwater conditions while driving as shown in Figure 4 below. The control box contained a video screen and a joy stick to be used by the operator to control to steer the device. The submersible vehicle had four motors used for forward and reverse movement and up and down movement. ROS also used halogen lights for illumination.

\section{FIGURE 4 ROS CONTROLLER}

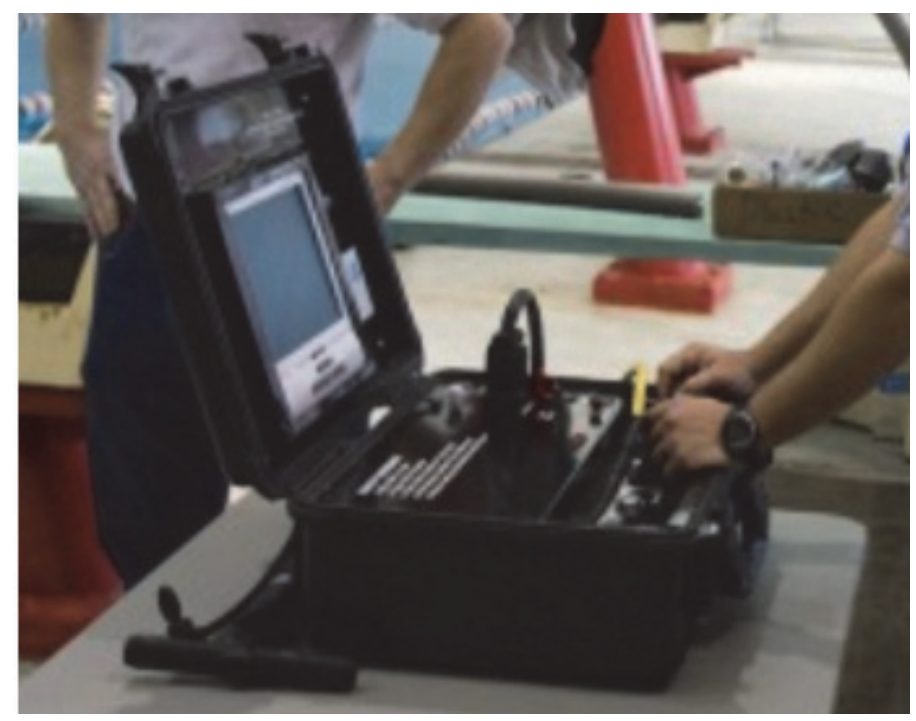

The alpha prototype weighs approximately $24.6 \mathrm{lbs}$ with the dimensions 17"x14"x10". The ROS body was obtained by Warren County Search and Rescue from Can-Am, a company which no longer exists. The cost of the ROS components without the cost of the body was approximately $\$ 4300$ as shown in Table 1 below. The majority of the cost was the thrusters, the motor controllers, and the halogen lights. Table 2 lists the cost of the major components of the ROS controller. 
TABLE 1

LIST OF MAJOR COMPONENTS IN ROS VEHICLE

\begin{tabular}{|l|l|l|l|}
\hline Item & Quantity & Cost/Unit & $\begin{array}{l}\text { Total } \\
\text { Cost }\end{array}$ \\
\hline Motor Controller & 2 & $\$ 80.00$ & $\$ 160.00$ \\
\hline Microprocessor & 1 & $\$ 60.00$ & $\$ 60.00$ \\
\hline Halogen Lights & 4 & $\$ 19.00$ & $\$ 76.00$ \\
\hline Thrusters & 4 & $\$ 950.00$ & $\$ 3800.00$ \\
\hline Camera & 1 & $\$ 70.00$ & $\$ 70.00$ \\
\hline Tether (40') & 1 & $\$ 80.00$ & $\$ 80.00$ \\
\hline DC Convertor & 1 & $\$ 40.00$ & $\$ 40.00$ \\
\hline Miscellaneous Parts/Electronics & & & $\$ 30.00$ \\
\hline Housing (provided by WCSR) & & & unknown \\
\hline Total & & & $\$ \mathbf{4 3 1 6 . 0 0}$ \\
\hline
\end{tabular}

TABLE 2

LIST PF COMPONENTS IN ROS CONTROLLER

\begin{tabular}{|l|l|l|l|}
\hline Item & Quantity & Cost/Unit & $\begin{array}{l}\text { Total } \\
\text { Cost }\end{array}$ \\
\hline Joystick & 1 & $\$ 192.00$ & $\$ 192.00$ \\
\hline Microprocessor & 1 & $\$ 30.00$ & $\$ 30.00$ \\
\hline DC Converter & 1 & $\$ 350.00$ & $\$ 350.00$ \\
\hline LCD Screen & 1 & $\$ 395.00$ & $\$ 395.00$ \\
\hline Pelican Case & 1 & $\$ 160.00$ & $\$ 160.00$ \\
\hline Circuit Board & 1 & $\$ 10.00$ & $\$ 10.00$ \\
\hline Total & & & $\$ \mathbf{\$ 1 1 3 7 . 0 0}$ \\
\hline
\end{tabular}

The ROS has many uses for search and rescue but also has many limitations. In underwater cave exploration, the areas are often unknown and there is a risk of damage to the robot or loss of the robot. The cost of the robot would make the user wary of exploring passageways in where the robot could be irretrievable.

\section{Beta Prototype (Narwhal) Development}

After the development and testing of the alpha prototype, the interdisciplinary team engaged in preliminary discussions with various constituencies to determine the significance of this product. Through conversations with interdisciplinary team and from the WKU Center for Cave and Karst Studies (CCKS) and Lost River Cave, it was determined that a remotely operated vehicle with the following capabilities would greatly aid cave exploration:

- Ability to explore underwater areas that might be dangerous or even prohibitive for human divers;

- Ability to maneuver small caverns and passageways in underwater caves;

- Ability to measure the size of underwater cave passages;

- Ability to collect water samples and specimens; and

- Low manufacturing cost in the event that the vehicle cannot be recovered.

Through similar conversations with interdisciplinary team and from the WKU Civil Engineering Program, it was determined that an inexpensive remotely controlled underwater vehicle with the following capabilities would be valuable for bridge inspection:

- Ability to detect bridge scour; 
- Ability to view the underwater structure of bridges in areas that may be unsafe to divers; and

- Low manufacturing cost in the event that the vehicle cannot be recovered.

From these discussions, the engineering team designed the second prototype which would meet the following criteria:

- Small;

- Portable;

- Remotely controlled; and

- Inexpensive.

The new robot, named Narwhal---working name, has an internal video camera that transmits video to the controller via tether similar to the initial prototype. During the design phase, all new components of the robot were chosen including a new microcontroller, motors, motor drivers, propellers, robot body, video camera, and any electronics associated with these devices.

A diagram of the Narwhal is shown in Figure 5 below.

\section{FIGURE 5 \\ NARWHAL, TOP VIEW}

\section{Thruster}

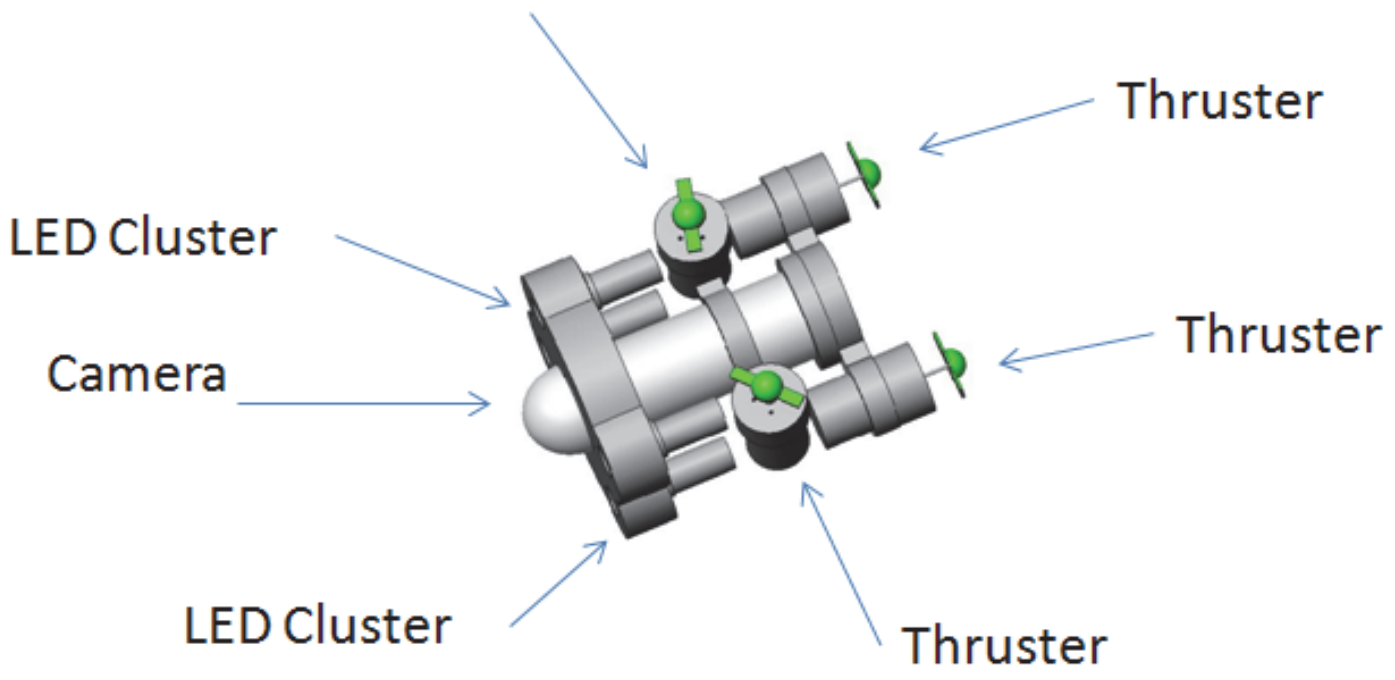

Extensive testing occurred which included the following:

- LED clusters were tested in a dark room to determine the effects of different colors of lights (Red, blue, green, white, and yellow) on the camera system of the submersible.

- Thrusters were tested for water tightness, load thrust, produced power consumption at no load and under the required load need to propel the submersible. The mounting brackets of thruster were tested and the thrusters were impact tested.

- Outer casing was tested for water tightness and designed to eliminate snag points. The outer casing was also impact tested.

- The controller and processor were tested for power consumption and communication durability.

- The vision system was tested in dark room for resolution under a variety of lighting sources including halogen and LED lighting.

- The cameras were tested to determine lux under a variety of lighting sources and to determine the effects to vision of the user. 
Indoor testing of the beta prototype was successfully and later so was the outdoor testing. The following Pictures shows the Robot being tested in a local river near Bowling Green, KY ...now named Pioneer.

\section{FIGURE 6 \\ PREPARING TO LAUNCH ROBOT---PIONEER}

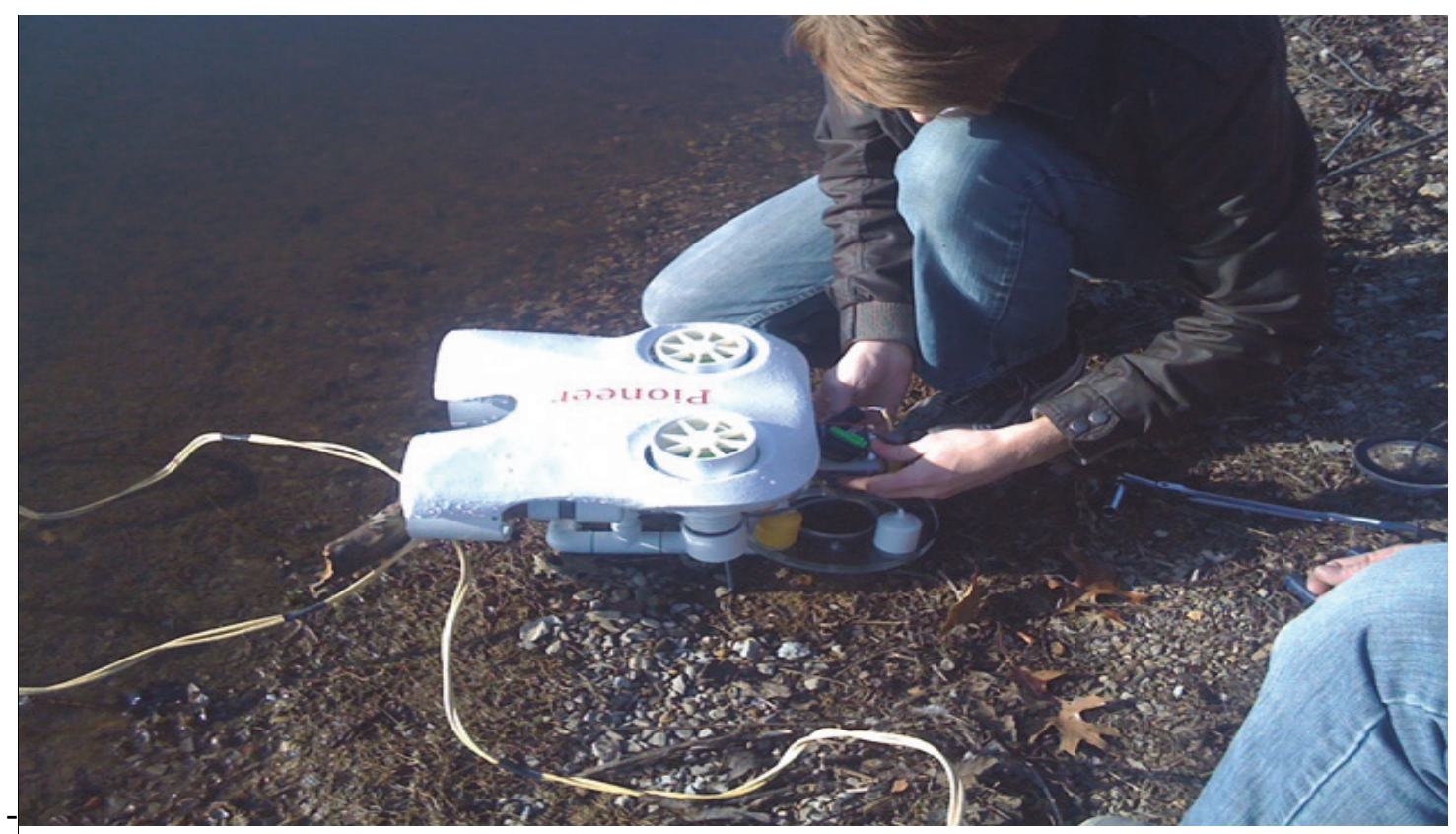

FIGURE 7

ROBOT TESTING

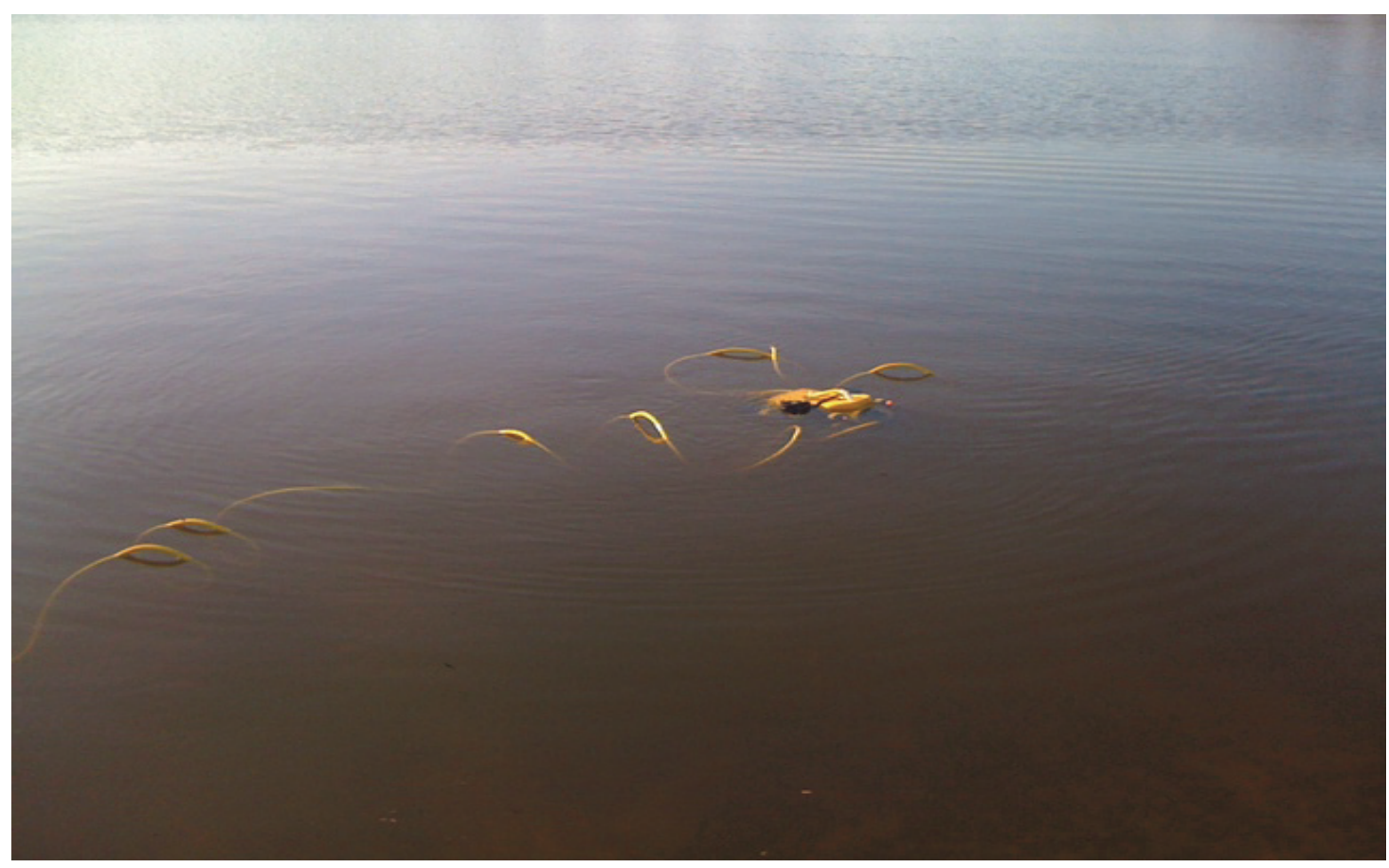

122 Journal of Marketing Development and Competitiveness Vol. 13(2) 2019 
Several design changes occurred to lower the cost of the Narwhal compared to ROS. First, the cost of the lighting was reduced by designing LED clusters to be mounted on the front of the vehicle. Inexpensive motor controllers were also chosen to replace the motor controllers previously used. The thrusters were redesigned to be more cost efficient and a new body was developed from PVC pipe. The cost of the vehicle was reduced significantly by using many off the shelf products and developing parts by taking advantage of the manufacturing expertise of the engineering team. Tables 3 and 4 list the components in the Narwhal vehicle and controller.

TABLE 3

LIST OF COMPONENTS IN NARWHAL VEHICLE

\begin{tabular}{|l|l|l|l|}
\hline Item & Quantity & Cost/Unit & Total Cost \\
\hline Saber Tooth Motor Controller & 2 & $\$ 80.00$ & $\$ 160.00$ \\
\hline Adruino Mega 2560 Microprocessor & 1 & $\$ 60.00$ & $\$ 60.00$ \\
\hline LED Clusters & 4 & $\$ 8.00$ & $\$ 32.00$ \\
\hline Propellers & 4 & $\$ 13.00$ & $\$ 52.00$ \\
\hline Dome & 1 & $\$ 52.00$ & $\$ 52.00$ \\
\hline 12V DC Motor & 4 & $\$ 10.00$ & $\$ 40.00$ \\
\hline Camera & 1 & $\$ 70.00$ & $\$ 70.00$ \\
\hline Tether (40') & 1 & $\$ 80.00$ & $\$ 80.00$ \\
\hline DC Convertor & 1 & $\$ 40.00$ & $\$ 40.00$ \\
\hline Body & & & $\$ 50.00$ \\
\hline Miscellaneous Parts/Electronics & & & $\$ 30.00$ \\
\hline Total & & & $\$ 614.00$ \\
\hline
\end{tabular}

TABLE 4

LIST OF COMPONENTS IN NARWHAL CONTROLLER

\begin{tabular}{|l|l|l|l|}
\hline Item & Quantity & Cost/Unit & $\begin{array}{l}\text { Total } \\
\text { Cost }\end{array}$ \\
\hline Joystick & 1 & $\$ 73.00$ & $\$ 73.00$ \\
\hline Arduino Uno Microprocessor & 1 & $\$ 30.00$ & $\$ 30.00$ \\
\hline DC Converter & 1 & $\$ 40.00$ & $\$ 40.00$ \\
\hline LCD Screen & 1 & $\$ 58.00$ & $\$ 58.00$ \\
\hline Pelican Case & 1 & $\$ 160.00$ & $\$ 160.00$ \\
\hline Circuit Board & 1 & $\$ 10.00$ & $\$ 10.00$ \\
\hline Total & & & $\mathbf{\$ 6 5 5 . 0 0}$ \\
\hline
\end{tabular}

By comparing Tables 1 and 3, the Narwhal vehicle is significantly cheaper than the ROS especially since the ROS final cost does not include the cost of the body. Both robots use similar controller boxes however less expensive components where chosen for the Narwhal controller.

A comparison of the power consumption of the ROS and Narwhal are shown in Table 5. As seen from the table, the Narwhal consumes less power and thus would not require as much DC power as the ROS. 
TABLE 5

POWER CONSUMPTION COMPARISON BETWEEN ROS AND NARWHAL

\begin{tabular}{|l|l|l|}
\hline Component & Narwhal Power Consumption & ROS Power Consumption \\
\hline Lights & $1.7 \mathrm{~W}$ & $12 \mathrm{~W}$ \\
\hline Camera & $3 \mathrm{~W}$ & $3 \mathrm{~W}$ \\
\hline Processor & $0.5 \mathrm{~W}$ & $0.5 \mathrm{~W}$ \\
\hline Motor Controller & $1.5 \mathrm{~W}$ & $1.5 \mathrm{~W}$ \\
\hline Thrusters & $144 \mathrm{~W}$ & $192 \mathrm{~W}$ \\
\hline Total & $\mathbf{1 5 0 . 7 W}$ & $\mathbf{2 0 9 W}$ \\
\hline
\end{tabular}

The Narwhal, shown below in Figure 6, has dimensions of 17"x13.5"x10.5" and weighs approximately $16 \mathrm{lbs}$. The following improvements were made to the beta prototype:

- Smaller design of the controller;

- Lights upgraded from halogen to LEDs;

- Reduced the power consumption by more than $50 \%$; and

- Improvement of the usability of the controller for the end user.

Figure 6: Narwhal Beta Prototype

Comparison of Narwhal to State of the Art Technology

Most of the current underwater vehicles are designed and marketed for salt water applications [1]. Many devices with similar function on the market are larger than the new Narwhal. Also, the Narwhal system uses a DC marine or car battery for power. Existing devices are powered by AC voltage and will require a portable generator for use. Since the Narwhal is simply powered by a DC power supply and does not require an $\mathrm{AC}$ generate, it will be easier and faster to deploy than existing devices.

The major competitor for the Narwhal is manufactured by VideoRay (http://www.videoray.com/). The VideoRay remotely operated vehicle has been used in bridge inspection research. (Murphy, R.,Steimle, E., Hall, M., Lindemuth, D., Trejo, S., Hurlebaus, Medina-Cetina, Z. \& Slocum, D. 2009).

Table 6 below shows the comparison between the systems manufactured by VideoRay and the Narwhal. A detailed comparison of the Narwhal and VideoRay submersible vehicles and controller units is presented in Tables 7 and 8 , respectively.

TABLE 6

COMPARISON OF NARWHAL AND VIDEORAY SYSTEMS

\begin{tabular}{|l|l|l|l|l|}
\hline & Scout & Explorer & PRO 3 GTO & Narwhal \\
\hline Manufacturer & VideoRay & VideoRay & VideoRay & WKU \\
\hline Power & 800 Watts & 800 Watts & 800 Watts & 150 Watts \\
Requirements & $100-240 \mathrm{VAC}$ & $100-240 \mathrm{VAC}$ & $100-240 \mathrm{VAC}$ & $12 \mathrm{VDC}$ \\
\hline Total Weight & $70 \mathrm{lbs}$ & $95 \mathrm{lbs}$ & $135 \mathrm{lbs}$ & $16 \mathrm{bs}$ \\
\hline Base Price & $\$ 6,495.00$ & $\$ 10,495.00$ & $\$ 31,995.00$ & $\$ 1269.00$ \\
\hline
\end{tabular}


TABLE 7

SUBMERSIBLE VEHICLE COMPARISON

\begin{tabular}{|c|c|c|c|c|}
\hline & Scout & Explorer & PRO 3 GTO & Narwhal \\
\hline Manufacturer & VideoRay & VideoRay & VideoRay & WKU \\
\hline Depth Rating & $250 \mathrm{ft}$ & $250 \mathrm{ft}$ & $250 \mathrm{ft}$ & $250 \mathrm{ft}$ \\
\hline \multicolumn{5}{|l|}{ Propulsion } \\
\hline Number of Thrusters & 2 & 2 & 2 & 4 \\
\hline Propeller Size & $50 \mathrm{~mm}$ & $50 \mathrm{~mm}$ & $100 \mathrm{~mm}$ & $76 \mathrm{~mm}$ \\
\hline Type of Drive & Geared & Geared & Geared & Direct \\
\hline \multicolumn{5}{|l|}{ Camera } \\
\hline Camera Location & Front & Front & $\begin{array}{l}\text { Front and } \\
\text { Back }\end{array}$ & Front \\
\hline Type of Angle & Wide & Wide & Wide & Wide \\
\hline Type of Picture & Colored & Colored & Colored & Colored \\
\hline Number of Resolution Lines & 420 & 570 & 570 & 380 \\
\hline Lux & 0.3 & 0.3 & 0.3 & 0.3 \\
\hline Tilt & None & Variable & Variable & None \\
\hline \multicolumn{5}{|l|}{ Lighting } \\
\hline Number of Lights & 2 & 2 & 2 & 4 \\
\hline Lights Power Consumption & $20 \mathrm{~W}$ & $20 \mathrm{~W}$ & $20 \mathrm{~W}$ & $0.432 \mathrm{~W}$ \\
\hline Type of Light & Halogen & Halogen & Halogen & Halogen \\
\hline Intensity Control & Variable & Variable & Variable & None \\
\hline
\end{tabular}

TABLE 8

CONTROLLER COMPARISON

\begin{tabular}{|l|l|l|l|l|}
\hline & Scout & Explorer & PRO 3 GTO & Narwhal \\
\hline Manufacturer & VideoRay & VideoRay & VideoRay & WKU \\
\hline Main Display & 7' color & 7” color & 15 ' color & 7” color \\
\hline Type of Control & Joystick & Joystick & Joystick & Joystick \\
\hline Depth Control & Yes & Yes & Yes & Yes \\
\hline Camera Tilt and Focus & No & Yes & Yes & No \\
\hline Lighting Control & No & Yes & Yes & No \\
\hline
\end{tabular}

The uniqueness of the new technology is that the new device is significantly less expensive than the submersible vehicles on the market.

\section{Project Goal}

The goal of this project was to commercialize the Narwhal submersible robotic vehicle system. The objectives of this project were to designing the vehicle for manufacturing; finding the cheapest sources for components and compiling a list of vendors; developing the manufacturing process; creation of the engineering drawings; testing of manufacturing process and design; conducting market research; and creating the commercialization plan. As part of the commercialization plan, a solid market entry plan will be created along with a clear understanding of potential customers, partners, investors, and competitors.

Three Narwhal systems were developed. Each system included the submersible vehicle, joystick, and 40 ' of tether. The standard model will also include a controller with a 7" color monitor. The elite model included a controller with a 12 " color monitor. The basic model will not include a controller but will include software that can be used to interface between a joystick and the vehicle. This software has already been by developed by a local company, Custom Solutions and Design, who has partnered with the 
design team to provide this software for the basic option. The table below summarizes the options of purchase.

TABLE 9

\section{CUSTOMER OPTIONS FOR NARWHAL SYSTEM}

\begin{tabular}{|l|l|l|l|}
\hline & Narwhal Basic & Narwhal Pro & Narwhal Elite \\
\hline Vehicle & $\$ 544$ & $\$ 544$ & $\$ 544$ \\
\hline Joystick & $\$ 30$ & $\$ 30$ & $\$ 70$ \\
\hline Tether & $\$ 80$ & $\$ 80$ & $\$ 80$ \\
\hline Controller & NA & $\$ 655$ & $\$ 655$ \\
\hline Software & $\$ 299$ & NA & NA \\
\hline Monitor Size & NA & $7 ”$ & $12 \%$ \\
\hline Camera & $\$ 70$ & $\$ 70$ & $\$ 300$ \\
\hline Estimated Price & $\$ 913$ & $\$ 1379$ & $\$ 1649$ \\
\hline
\end{tabular}

The tasks to be completed for project were divided into two categories: manufacturing and commercialization. The first manufacturing task was to complete the validation of the design by the Engineering Team and redesign the product were necessary.

The tasks conducted by the Commercialization Team focused on preparing to launch the new company and to develop a market base.

\section{Market Assessment}

As an integral part of the interdisciplinary team, the entrepreneurs and marketers from The Center for Entrepreneurship and Innovation at WKU (Directed at that time by R. Wilburn Clouse) established a process of research and development for the robot to lead to a new start-up and commercialization of a new product. The Center was a campus-wide effort that maintained a symbiotic working relationship with the Ogden College of Science and Engineering at WKU. The Center was positioned to work directly with the Electrical Engineering Program to research and develop the commercialization of a remotely controlled submersible robot, the Narwhal. Working very closely with the engineering design team, the Center conducted a market assessment, develop a business plan concept and investigated the commercialization of the remotely controlled submersible.

\section{Market Size}

The interdisciplinary team developed potential markets for this new invention. Some of the markets would include:

- MARINE LIFE: This device would have the capability of searching underneath boats, docks, and other submerged items to detect debris and/or defects.

- CITY INFRASTRUCTURE: Many of the larger cities in Kentucky and surrounding areas are experiencing difficulty in the city-wide infrastructure and water and sewer systems. This device offers a detective technique.

- SEARCH AND RESCUE: This device could be used to help forensics identify objects underwater related to death and rescue missions.

- UNDERWATER PASSAGE SYSTEMS: Kentucky has a number of underwater passage systems in which this device could be very helpful to maintain pure water systems within Kentucky.

- TRANSPORTATION SYSTEMS: There are more than 8,000 bridges in the Commonwealth that may need inspection using underwater techniques. This could also be expanded to other states surrounding Kentucky. 
- WATER RECREATION: This device would be an excellent tool to investigate underneath submerged recreational boats as well as commercial boats

- EDUCATIONAL SYSTEMS: A package could be developed to use the underwater robot to teach concepts of robotics and water engineering. This could be made available to high schools and universities in the state of Kentucky and surrounding areas.

- WATER SYSTEM SUSTAINABILITY: This device could be used in water towers and other fresh water systems to investigate the current conditions within these vessels.

From the investigation of these markets and other markets, the cost of distribution were identified based upon the potential market size.

\section{Commercial Assessment}

Working closely with the Electrical Engineering Program and the Ogden College of Science and Engineering, and the Center for Innovation \& Entrepreneurship a commercialization process was developed based on the market studies and suggestions from potential venture capitalists to help fund the start-up of the commercialization process.(Clouse, R. W. 2013).

The Center utilized the expertise of the Center's steering committee which has expertise in venture capital and in new start-ups. The steering committee was composed of: Mo Miller, a venture capitalist and small business owner; Lisa Williams, director of the Elizabethtown Innovation and Commercialization Center; George Peterson, a local entrepreneur; Arthur Hutcherson, entrepreneur and commercial developer; and Noel McDowell, entrepreneur and creative thinker. The Center was led at the time of this project by Dr. R. Wilburn Clouse, Executive Director and the holder of the Mattie Newman Ford Endowed Chair in Entrepreneurship.

In order to enhance the project, students in the field of entrepreneurship were connected with students in electrical engineering to form a partnership to develop and commercialize this project. The knowledge and skills learned during this educational process greatly enhance these students to develop and implement, not only this project, but other projects. The start-up company, and the skills and knowledge learned during the process have the potential to have great economic impact on the region, both in the short-term and long-term.

\section{Commercialization process---- Design and Fabrication-naming process}

In the development of the commercialization process, the interdisciplinary team conducted a "jam" session to determine the name for the final product. When investigating a marketing strategy, the robot, the working name --- Narwhal did not offer much pizzazz. The team developed two different approaches for renaming the robot.... Functional names and Metaphor names.

The possible names developed are as follows:

\section{Functional Names}

Adventurer (Basic, Pro, Elite)

Pioneer Basic, Pioneer Pro, Pioneer Elite

Vanguard Basic, Vanguard Pro, Vanguard Elite

The Dart Basic, The Dart Pro, The Dart Elite

Discover1, Discover2, Discover3

Hydra Cam

Trek Spec

Sea View

Aqua Sight

Immersed Exposure

Neptune

Xplor Robotix 


\author{
Metaphoric Names... (Like apple for computer) \\ River Rat \\ Waves of the future \\ Frogs of the sea \\ Water wings \\ The Eagle of the Sea \\ Catfish eyes \\ Marlin Fins \\ Eyes and ears of the Dolphin \\ Shark Eyes \\ Eyes and Ears that see and hear under the water. \\ Technology of the sea... \\ Bluegill robot
}

As one might expect, the entrepreneurs favored the metaphoric names while the engineers leaned more toward the functional names....the functional names won...

The new product was thus named and descripted as follows:

$1^{\text {st }}$ level Basic System---Basic Pioneer

The submersible vehicle system is composed of two subsystems; a vehicle and controller. The controller and vehicle are connected via tether to relay power and control information between the controller and the vehicle. The submersible unit itself is equipped with a live feed video camera, LED lights for increased visuals, and four thrusters to control movement. The control box contains a video screen and a joystick to be used by the operator to control to steer the device, and allows the user to have a visual of the underwater conditions while driving the unit.

\title{
$2^{\text {nd }}$ Level System-----Pro Pioneer
}

This submersible vehicle has the same features as the Pioneer Basic, but is more powerful and has these additional Features: 4-LED light set, Small Controller /w 7" monitor and single Joy stick.

\section{$3^{\text {rd }}$ Level System---- Elite Pioneer}

This submersible vehicle has the same features as the Pioneer Pro, but is still more powerful and has these additional Features: LED Ring cluster light set, Larger Controller w/ 7" monitor and single Joy stick, high Definition Camera and can be special ordered with larger Controller w/15 "display, dual Joysticks control, 24 DC voltage, 11" and 12" chassis and Plastic Storage Case. 
Features of each model are shown in the following Table:

Under water submersible w/options

Standard Features with version of Submersible

Description:

Basic

Standard Submersible

(10" Chassis)

Two Vertical Thrusters

Two Horizontal

$\sqrt{ }$

$\sqrt{ }$
$\sqrt{ }$

Thrusters

Two LED Clusters

Four LED Clusters

LED Ring Cluster

USB Controller Box w/wireless router

Small Controller w/ 7"monitor and single joystick

Large Controller w/10" monitor and single joystick

Standard Definition Camera

High Definition Camera

Software

Options:

Large Controller w/15" Display

Dual Joystick Control

24 DC Voltage System

11" Chassis

15" Chassis

Large Plastic Storage

Case for Submersible

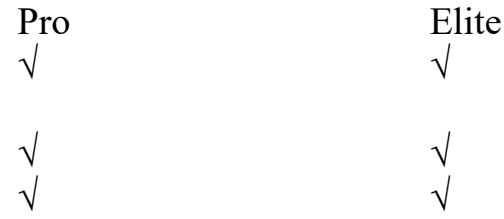

$\sqrt{ }$

$\sqrt{ }$
$\sqrt{ }$
$\sqrt{ }$

\section{Possible Markets----Realistic projections}

There are several possible markets for each model. Based on preliminary research we have identified the following eight markets and made some basic sales projections for years 1-3. These projections are based on reviews of other systems, interviews with field experts, literature reviews, Venture Capitalist and entrepreneur reviews. 


\section{Applications \\ Aquaculture \\ Fish Husbandry \\ Feeding Assessment \\ Net Inspection \\ Catfish Ponds}

Commercial Diving

Discovery

Educational/Research/Universities

Marine life

Environmental

Academic research

Infrastructure - state wide

Bridge/culvert inspection

Locks-dams-reservoirs

Tank inspection

Hydroelectric Plants

Law Enforcement

Homeland security

Port security

Search and recovery

Forensic

Offshore

Structural /Intake

Pipe inspection

Military

Mine detection

Port security

Sport/hobbyist

Boat docks

Yachting

Wreck diving

Caves exploring

Hobbyists

Marinas

Total
$1^{\text {st }}$ year
2-3
$2^{\text {nd }}$ year
$3^{\text {rd }}$ year
10-15
5-7

-

$1-2$

\section{1-2}

2-3

3-5

2-3

3-5

10-12

20-25

75- 100

3-5

7-10

10-12

0

1-2

3-5

\section{to be determined}

$\begin{array}{lll}2-3 & 3-5 & 7-10\end{array}$

$\begin{array}{lll}1-2 & 4-5 & 10-12 \\ 20-29 & 44-50 & 121-264\end{array}$

\section{Rational for Submersible Application}

Aquaculture

Aquaculture is the most rapidly expanding food industry in the world, and offshore fish pens are becoming heavily used in this industry. Underwater inspection is an important aspect in monitoring fish pens for feeding habits, fish health and structure damage. Using an ROV is the ideal solution to monitor offshore pens in a cost effective manner.

U.S. costs alone are home to thousands of fish pens. Each of these must be inspected on a regular basis to inspect for disease within the fish stock, and damage to the fish pen itself. Using an ROV is more cost effective for this industry expanding industry. Fish pens are sometimes damaged by storms and other natural causes, which may result in fish escape. This is frowned upon by environmental protection organizations as it may have negative consequences on native species. (Skladany, M., Clausen, R., Belton, B. (2007)

Local fish farms may also have a need for underwater inspection; however it is not a regular necessity as it is with offshore fish pens. According to Whiskers Catfish Farm, located in Bowling Green Kentucky, 
having an ROV would be convenient for monitoring fish habits, however regular inspection is not necessary.

University / Academic Science \& Research ROVs -

ROV's have proven an affordable and exceptional learning tool for academic users. The ROV system can both complement and at times replace other data collection platforms such as divers. The minimal logistics required makes getting in and out of the field as easy as possible. They have been used for ecological surveys and assessments, fishery studies, archaeology, under ice exploration, and other submerged academic applications. A list of Kentucky Public Universities, Community and Technical Colleges, Private Colleges and Colleges outside of Kentucky with campuses in Kentucky is listed below.

Education Market for Kentucky

Public Colleges and Universities

1. Eastern Kentucky University

2. Kentucky State University

3. Morehead State University

4. Murray State University

5. Northern Kentucky University

6. University of Kentucky

7. University of Louisville

8. Western Kentucky University

Community and Technical Colleges

1. Ashland Community and Technical College

2. Big Sandy Community and Technical College

3. Bluegrass Community and Technical College

4. Elizabethtown Community and Technical College

5. Gateway Community and Technical College

6. Hazard Community and Technical College

7. Henderson Community College

8. Hopkinsville Community College

9. Jefferson Community and Technical College

10. Kentucky Technical University

11. Madisonville Community College

12. Maysville Community and Technical College

13. Owensboro Community and Technical College

14. Somerset Community College

15. South-central Kentucky Community and Technical College

16. Southeast Kentucky Community and Technical College

17. West Kentucky Community and Technical College

Private Liberal Arts Colleges

1. Alice Lloyd College

2. Asbury University

3. Bellarmine University

4. Berea College

5. Centre College

6. Georgetown College

7. Kentucky Wesleyan College

8. Lindsey Wilson College

9. Midway College 
10. St. Catharine College

11. Thomas More College

12. Transylvania University

13. Union College

14. University of the Cumberland (formerly Cumberland College)

15. University of Pikeville

Other Colleges with campuses in Kentucky

1. Brown Mackie College

2. Daymar College

3. Indiana Wesleyan University

4. ITT Technical Institute

5. McKendree University

6. Southwestern College

7. University of Phoenix

We suggested that Kentucky be used as test state to prove the application to the Academic market during the first 2 years and then expand to other states especially states that are involved in water related research. Kentucky has 8 Public Universities, 17 Community and Technical Colleges, 15 Private Universities, and 7 Universities with Kentucky campuses and a host of specialist Colleges. The State Universities and Community and Technical Colleges offer the best markets at this time.

\section{Infrastructure}

\section{Potable Water Tanks}

Potable water tanks must be regularly inspected to insure safe drinking water for the public. ROV inspection provides a cost efficient solution to potable water tank inspection. Without using an ROV, the methods to inspect a water tank include draining the entire tank reservoir or using a human diver, both methods being more costly than using an ROV. Using an ROV reduces risk if water contamination, and does not interfere with tank operation.

Ron Perrin is an industry leader in potable water inspection; he is an industrial consultant for the WKU commercialization project. Perrin currently uses a VideoRay ROV in his tank inspection process. According to Perrin, the cost of ROV tank inspections can range from $\$ 500-\$ 6000$, with costs being even higher when an ROV is not used. He has also informed us that new regulations to be imposed by the EPA may increase the need for ROVs within this market.

"According to my source at the EPA, there may be some dramatic changes regarding inspection rules in the near future that would place your product in a very good position if you can bring it to market in the next year."

The Kentucky Division of Water has also confirmed this likely change in regulation.

"It is anticipated that EPA may issue guidance on storage tank inspections later this year in conjunction with the recently published Revised Total Coliform Rule"

Julie Roney, of the Kentucky Division of Water, says most inspections still involve draining the tank for the manual inspection, then disinfecting, refilling the tank and doing the microbial testing - this can take time and may be costly in terms of disinfectant used and volume of water needed to properly disinfect. There is an AWWA underwater inspection protocol that we have used in the past and there is at least 1 company in KY that does such inspections - usually with divers. Underwater inspections typically don't involve draining the tank as the diver and equipment are disinfected prior to entry. 
The current inspection rate is on average every 5-10 years in Kentucky. The anticipated EPA issue will most certainly require tanks to be inspected much more frequently, thus creating a demand for AWWA underwater inspections within the water storage tank network.

Kentucky has 457 public water systems. Each water system has at least 1 water storage tank, some public water systems have as many as 100 tanks. These tanks range in size from 1000 gallons to $15 \mathrm{MG}$ storage reservoirs. Kentucky alone has thousands of potable water tanks, thus creating a enormous potential market. However this market extends much farther than Kentucky; New York City is home to over 10,000 rooftop water towers. According to Bill Hence, in the Tennessee division of water, the state has over 500 municipal water companies. Each of these public water systems has an average of 5-6 water towers, which are required by the state of Tennessee to be inspected every 5 years. The estimated 3,0004,000 water towers in Tennessee are currently inspected by either a human diver, or an ROV. However, any change in EPA regulation will require the tanks to be inspected much more frequently, creating a huge market advantage if the WKU device can be brought to commercialization before the regulation takes effect.

\section{Bridge \& Culvert Inspection}

ROVs have proven themselves as one of the easiest, safest, and most cost-effective solutions for underwater structure inspections. The portable system can easily be deployed and piloted by a single operator while capturing high resolution color video for documentation needs. This methods avoids putting human divers in potentially dangerous environments, an ROV is also capable of inspecting small diameter pipes and culverts.

Josh Rogers, who works in the Kentucky Transportation Cabinet, oversees underwater bridge and culvert inspection for the state of Kentucky. He claims the WKU device could be very beneficial to underwater inspection. According to Rogers, in Kentucky there are around 300 structures that require inspection by the Federal Highway Association. These structures are required to be inspected at intervals of 60 months. The state currently employs Stantec, a large industrial consulting company, to inspect a majority of these structures.

Stantec claims the ROV device would be very useful for deep water inspections, such a pier in Herrington Lake. The ROV would also be useful for underwater penetration in pipes and outtakes. The company also claimed the ROV would have drawbacks in certain scenarios. Many of its inspections are done by feel, because of murky water conditions. In some inspections, vegetation and algae growth must be cleaned prior to inspection. However, assuming the FWHA approved inspections done the WKU ROV, this unit would be very helpful in certain scenarios.

\section{Dams, Locks \& Reservoirs}

Agencies like the Army Corp of Engineers and the U.S. Bureau of Reclamation use ROV units to aid in the inspection of dams, locks \& reservoirs. Kentucky is home to 14 navigation locks and dams; these are currently inspected by the Army Corp of Engineers. In 2011, Kentucky was reported to have 967 State Regulated Dams. According to the Kentucky Dam Safety Program, 169 of these dams are considered to be high hazard. The hazard rating is determined by the consequences of dam failure, not the condition of the dam itself. Additionally, Kentucky's State Dam program employs 5 full time employees, and operates with a budget of $1,500,000$.

The routine inspection of dams and locks are imperative to the safety of the public. These programs operate with large budgets, and could tangibly benefit from the WKU ROV. Marilyn Thomas, a WKU graduate who works in the Kentucky Dam Safety Division, has already began using ROVs in the inspection process of dams, submerged spillway structures, gates and other infrastructure. Every dam is required to be inspected every 60 months, with higher hazard dams inspected at 24 month intervals. http://water.ky.gov/damsafety/Pages/default.aspx 


\section{Offshore Drilling and Oil Rigs}

After reviewing our competition's market placement we found that offshore drilling was a huge potential market for our submersible in the future. There are tons of oil rigs in the waters surrounding the United States alone, each of those has a huge network of cables and pipes that routinely need to be inspected. Much of these cables and pipes are very deep under the surface of the water. With further development of our product we could be able to fulfill those needs. Our submersible is priced low enough that we could place one on every oilrig in order to do the regular inspections that are required, this would eliminate time money wasted of placing a diver in the water to inspect or spending thousands more on a very expensive submersible. Most of the inspection process for the rigs is done at a very deep depth, our submersible will have to be modified in order to fulfill the needs of these inspections which is why we view this as a future market.

\section{Law Enforcement}

Search \& Rescue

Search \& Rescue often puts divers in arms way, and often times the chances of finding a victim are small in these dangerous situations. With an ROV, searching for a victim can be safely and effectively conducted without putting human divers at risk. When the victim is located divers can be called for a quick recovery by following the ROV tether directly to the victim.

Officer Chad Crick, head of the dive team and river patrol for the Louisville Police Department, has experience using ROVs. The LMPD River Parol currently have a JW Fishers SeaLion ROV which they purchased after receiving funds from a Port Security Grant in 2006 . There unit was $\$ 68,000$ new. It is currently in need of repairs; however it was used heavily for the first few years it was in operation.

The river patrol primarily used their ROV while searching for drowning victims in lakes around Kentucky. Specifically, they used the unit in scenarios where a body was suspected to be in 40-90 ft of water. Officer Crick explained, in most scenarios, it is easier for divers to search shallow waters, 20-30 ft. Deeper water limits a human's dive time; for example the average diver will only be under for 15 minutes in 90 feet of water. In a scenario like this, it is considerably more effective to use a ROV.

According to Officer Crick, one important element of the river patrol's submersible is the side scan sonar. They would often sit the ROV on the floor of the lake, and then use the sonar sweep the area to locate a body. After a body was located, two divers would be sent down to retrieve it.

Their unit was never extensively used in large rivers. Crick claimed that their unit was "swept away" in 1-2 knot currents. However, Crick recalls dozens incidents in the area when the ROV was successfully used to find a submerged object. He states that all search and rescue teams have considerable use for an underwater ROV.

Under the Kentucky Revised Statutes chapter 39F, Kentucky has developed a program to support the function of county and local search and rescue squads. Many of these squads would find value in having an ROV, and in some instances could use state funding to purchase this device. WKU's ROV is a very cost efficient way to implement this helpful technology in the search and rescue process.

\section{Military}

Because of the inexpensive nature of the submersible it lends itself to many applications. One of those is military use in the cases of port security and dangerous object detection such as mines or underwater explosives. The submersible contains a vivid camera and powerful thrusters that would allow the authorities to routinely inspect all areas of their ports without having to spend the time and extra money of having divers go in the water. This product could be a huge help to harbormasters and homeland security if properly applied. Though this is a potentially large market, as there are over 12,000 marinas in the US and thousands of saltwater ports, we do not project this as a current market. The submersible would need to undergo further testing by the people who would be using it for this application in order to see if there would need to be any modifications to it to suit the specific application in this instance. We do project this as a future market once our models are further advanced and better established. 


\section{Commercial Dive Teams and Marina}

Commercial dive teams have adopted ROVs into practical, everyday use. A portable ROV is perfect for times when deploying human divers is dangerous, or unnecessary. Robert Börjesson is a marketing director for Marine Vision, a major European ROV distributor. According to Börjesson,

"We sell mostly to law enforcement and commercial diving companies, the later uses the ROVs for inspection and diver-assistance"

These dive teams see a very practical application for ROV units, using them for pre \& post dive inspection. Common tasks for commercial dive teams include: underwater welding, infrastructure inspection, boat cleaning, hazardous material diving, etc. An ROV is a very practical aid for the commercial diving market.

Marinas are perhaps the largest industry for commercial divers. Marinas require the use of commercial divers for boat, net, marina, pier, and mooring inspection. This can be a very costly service for marinas to outsource, it is also very time consuming for commercial dive teams. The WKU ROV provides a cheaper, less time consuming method for commercial dive teams. Instead of immediately sending a diver into to inspect a pier, or mooring, drop the Pioneer in the water and use it to do the inspection.

There is huge potential, because of its cheaper cost, for marketing this product to commercial dive teams and marinas in order to eliminate extra, time, money, and danger that comes with sending a diver into the water to do routine inspections. There are 60 registered marinas in the states of Kentucky and Tennessee. Each of these marinas could use our product to add value to their businesses or to inspect their own equipment. Not to mention there are over 12,000 registered marinas in the entire country, our product could quickly become a huge asset to this market. Many of the moorings in these marinas require inspection, by either the marina itself or the boat's insurance company, annually or every two years. The Pioneer would allow these marina owners to provide this service of inspection to their owners, and could insure safety by checking their equipment in the water. Our products competitive advantages of price and ease of use make it widely applicable in the marina and commercial diving markets.

Hull inspection is another application for the submersible unit. In this segment, the ROV could be marketed to marinas and directly to consumers alike. Visual hull inspection is a necessity in regular boat inspection. According to the NMMA, there are over 17 million boats in the US; the great majority of these boats are relatively small, and if necessary can be docked and inspected above the water. However, marinas would still find great value in being able to make an underwater visual hull inspection. Yacht owners also are a target market for the device. Yacht owners may find value in the peace of mind a submersible unit provides, with its ability to instantly visually inspect expensive yachts.

\section{Hobbyist}

The WKU submersible unit is a fraction of the cost of similar units on the market, opening up a huge potential market in hobbyist users. This market segment will not function within one particular industry, but rather a large array of industries. The difference between hobbyist and all other potential market segments is hobbyist will find value through the recreational uses of the device.

Yacht owners are one example of a hobbyist market. Many yacht owners may have a desire to explore ocean reefs, while they may not have the ability or desire physically enter the water. The WKU submersible allows hobbyist to navigate through beautiful coral reefs from the comfort of a yacht while a 15 inch color display provides excellent visuals at depths of 5-150 feet deep.

Another hobbyist market segment is the fishing industry. Freshwater bass fishermen can use the device to inspect deeper water structure, survey spawn activity, analyze lure/jig presentation, or even inspect their bass boat. Many fishermen take this sport very serious, sometimes spending upwards of $\$ 500$ for a single rod, or $\$ 20$ for a single lure. Professional and recreational fishermen alike spend a considerable amount of money on gear, in hopes that it will produce more fish caught. At the low price 
point of the submersible, fishermen will easily be able to justify spending money on this portable device if they can use it to catch more fish.

The WKU submersible was developed for underwater exploration. All other similar devices have isolated themselves from this large target market with such high pricing structures. With similar features, the WKU device can successfully dominate the market with all hobbyist desiring underwater imaging.

\section{Operational Models}

Strategies

Now, that we have identity 8 different markets, how best do we reach these markets. There are several approaches:

1. Develop a sales team of 3-4 people and divide up the 8 markets and move swiftly on all markets.

2. Develop a sales team of 2-3 people and select 2-4 markets and move swiftly on those markets.

3. Develop a team of 1-2 people and concentrate on the most favorable market. Develop that market first and develop lateral marketing approaches to other related markets....From our work we support this approach at least for the first year as a pilot year and in the 2-3 years expand to related markets.

\section{Company Models}

Model 1- In company model one an LLC would be formed from WKU that would approach the already established contactors that perform the inspections of water towers, such as Ron Perrin, and set up the licensing of our product for their companies to use. This company would require the least amount of work to start and run. It would require the actual fees to form the company, a lawyer in order to draw up the licensing contracts for the state contractors, and one employee to sell the licensing agreements to the contractors. After licensing agreements were accomplished it would be a need based manufacturing model for the creation of the submersibles. We would supply the submersibles in exchange for a certain percentage from each contract it is used on. The company would be required to maintain the submersibles so the employee would have to be well versed in the maintenance of the product. By providing the submersible free to the contractors in exchange for a piece of each of their contracts the company would limit its responsibilities to production and up keep of its submersibles. If the maintenance cycles were long then there would be little time or money spent on the up keep and they company would collect off the contracts. This model would require more up front work (getting the licensing agreement, and building the appropriate number of submersibles) and then less along the way in order to sustain the business. (Most likely we would call on graduate students to help launch this venture, thus lower salary cost for the startup).

1 Employee- $\$ 35,000$

Marketing- $\$ 5,000$

Formation of company and Contract Licensing Agreement- \$1,500

Company Expenses (computers, office and supplies, etc...) $=\$ 3,000-\$ 4,500$

Pioneer Elite Manufacturing 4-8=\$8,000- $\$ 16,000$

Miscellaneous $=\$ 5,000$

Total $=\$ 57,500-\$ 67,000$

Model 2- In company model two an LLC would be formed that had the purpose of solely selling the submersible to any of the 8 markets, with a specific focus on water towers, outlined in the market research. This company would have a decently high startup cost as it would be required to creating marketing campaigns, hire 2-3 employees and create a manufacturing process that could supply the potentially high demand of the product. The 2-3 employees would focus their efforts on getting the word 
out about the product to all potential buyers. This job would require a lot of travel and would likely include some type of commission as to incentivize the employees doing the selling.

2-3 Employees- $\$ 60,000-\$ 90,000$

Travel Reimbursement- $\$ 5,000-\$ 7,500$

Marketing- $\$ 15,000$

Formation of company- $\$ 1,000$

Company Expenses (computers, office and supplies etc...) $=\$ 4,000-\$ 5,000$

Miscellaneous $=\$ 5,000$

Commission per unit sold $=5 \%$

Total $=\$ 90,000-\$ 123,500$

Model 3- In company model three an LLC would be formed for the purpose of competing for the contracts to do the water tank inspections for the state. This would be the most costly of all the models to start because you would have to hire at least one person who knows how to do the inspections. Next you would have to bid against companies at the state level to be able to do the inspections. With the low price of the submersible the overall cost of the bid would go down which would allow this company to undercut its competition. To be able to make this company work you would need to have several employees (2-4) who knew how to bid the inspection jobs and how to do the inspections. Next you would need equipment such as a truck, office, several of the Pioneer Elites, and finally tank cleaning gear. This company would start out solely focusing on the water tank inspection market but if it had success could move to bridge, dam, culvert, and marina inspection markets. This company would make all of its profits off of the contracts for the inspections. It would not pay to create the submersible so the money for the creation of each used would have to be recuperated within the deal with the state. Very little money would need to be spent on marketing for this company since all of its business is focused on delivering the service of inspection and cleansing, the submersible would just be the tool that enables that service to happen.

$2-4$ employees $=\$ 70,000-\$ 140,000$

Transportation $=\$ 10,000$

2-4 Pioneer Elite Submersibles $=\$ 4,000-\$ 8,000$

Office equipment (computers, office and supplies, etc...) $=\$ 5,000$

Formation of Company and marketing materials $=\$ 5,000$

Miscellaneous $=\$ 10,000$

Total $=\$ 104,000-\$ 178,000$

\section{Legal Process}

The legal process to take the submersible to the market may take several different models.

Model 1---Establish a LLC and determine the market over a 3 year period. This would require venture capital start up. After establishing the market niche-- 3years--- sell the LLC to a vender who already markets other products to this market. We recommend this model.

Model 2--- Develop patents and licenses the products to another company.

Model 3-Joint with an existing company that sale to the market with other complementary products.

\section{Competition Review}

The following list provides competitive information on other systems on the market at this time. The cost for each model is also shown. The prices for each ROV is shown with the lowest cost model at about $\$ \mathbf{5 , 2 0 0}$ up to systems selling $\$ \mathbf{5 1 , 0 0 0}$. 
1. JW Fisher, SeaOtter 2-

500 foot Depth

Front and rear facing Color cameras with tilt and Pan

250 feet of Cable

4 thrusters

10.4 inch monitor

2- 50 watt lights on front

LED light ring on back

PS2 Controller for ease of use

Video and Audio amp for better picture and sound

Two year warranty

2. JW Fisher, SeaLion 2-

1,000 foot depth

Front and rear facing Color cameras with tilt and Pan

250 feet of Cable

4 thrusters $\mathrm{w} /$ power boost

2- 100 watt lights on front

15 inch monitor

LED light ring on back

PS2 Controller for ease of use

Video and Audio amp for better picture and sound

Two year warranty

VideoRay, The Scout-

250 foot Depth

1.9 knots

7 inch display screen

3 thrusters, 2 horizontal, 1 vertical

40 meters of tether

Color camera 90 degree horizontal 140 degree diagonal view

2- 20 w halogen Lights

3. VideoRay, The Explorer-

250 foot Depth

1.9 knots

7 inch display screen

3 thrusters, 2 horizontal, 1 vertical

40 meters of tether

color camera 90 degree horizontal 140 degree diagonal view

2- $20 \mathrm{w}$ halogen Lights

Compass and depth Gauge

4. SeaBotix, LBV 150-

150 meters or 500 feet Depth

328 feet of tether

3 knots max speed can handle a current of 2 knots

4 thrusters 2 forward one vertical one lateral

90 degree view with 180 degree tilt

700 lumen LED

Depth, heading, and temp display 
5. SeaBotix, LBV 200-

200 meters or 660 feet Depth

328 feet of tether

3 knots max speed can handle a current of 2 knots

4 thrusters 2 forward one vertical one lateral

90 degree view with 180 degree tilt

700 lumen LED

Depth, heading, and temp display

6. GNOM, BABY-

50 Meters or $165 \mathrm{ft}$

35 meters of tether

2 knots max speed

2 clusters of LEDs

Color camera w/ tilt option

3 thrusters 2 forward 1 horizontal

7. GNOM, STANDARD-

150 meters max depth

80 meters of tether

3 knots max speed

2 clusters of LEDs

Color camera w/ tilt option

4 thursters 2 forward 2 horizontal

Auto Depth Sensor

8. GNOM, SUPER 2-

200 meters max depth

3 knots max speed

4 thrusters 2 forward 2 horizontal

4 clusters of LEDs

Color camera w/ 100 degree tilt

Auto Depth Sensor and on screen display

9. GNOM, SUPER PRO-

300 meters max depth

3 knots max speed

5 Thrusters

150 meters of tether

4 LED Clusters with 100 degree tilt

Camera with 100 degree tilt

The following 2 pictures show the Videoray and other technical details about Competitive Products can be found the Websites shown in appendix I.

JW Fisher-

http://www.jwfishers.com/rov.htm

SeaBotix-

http://www.seabotix.com/products/lbv200-4.htm

GNOM- 
http://www.gnom-rov.com/products/gnom-baby/

http://www.gnom-rov.com/products/gnom-standard/

http://www.gnom-rov.com/products/super-gnom/

http://www.gnom-rov.com/products/super-gnom-pro/

VideoRay-

http://www.videoray.com/homepage/economy-configurations/videoray-explorer.html

http://www.videoray.com/homepage/economy-configurations/videoray-scout.html

Pricing-

SeaOtter2-\$19,995

SeaLion 2-\$28,995

LBV 150-\$29,995

LBV 200-\$35,495

GNOM BABY $-\$ 5,232$ or $\$ 8,283$

GNOM Standard- $\$ 9,736$ or $\$ 14,386$

Super GNOM 2-\$20,344 or $\$ 34,875$

Super GNOM PRO-\$51,005

The Scout- $\$ 9,999.95$ or $\$ 13,999.95$

The Explorer-\$6,348.95

The websites shown in appendix I provide pictures and other details for competitive products.

\section{Commercialization Support Materials}

A complete set of marketing materials will be required in order to build a brand name and market the ROV. Some examples are listed below.

1. Website with examples and pricing information

2. Commercial Brochures with pictures of the robot in action

3. Conferences to demo the product

4. Sales calls on target market

5. News releases

6. Test sites for research and publication of data

7. Training manual

8. Training sessions

\section{SUMMARY AND CINCLUSIONS}

Most universities are structured around subject content and thus are divided into colleges and universities based on subject content. The subjects are taught in a structured learning environment and in most cases University professors find it difficult to leave the comfort of their chosen academic field. This project defied all the laws of organizational structures. (Clouse, R. W. \& Goodin, T.L. 2001). It involved engineering professors, entrepreneurship professors, active entrepreneurs and a host of undergraduate and graduate students in business, marketing, entrepreneurship, civil engineering, electrical engineering and manufacturing to develop a multidisciplinary approach to developing and marketing an underwater robot. The project began with the concept idea and ended with a process to commercialize a product developed within the University structure. The multidisciplinary approach simulated a real-world authentic environment and thus provided both faculty and students with an engaging, experiential learning experience (Clouse, R. W., Goodin, T., Aniello, J. S., Roberts, J. \& Stowe, C. 2011).

As indicated by this model, problem-based learning is an attempt to develop a real world learning environment where students are faced with complex issues, the need to develop innovative inquiry approaches to business ventures and the need to learn about ambiguity and uncertainty in real-live projects. 
In this learning in action project, we sought to develop an experiences that would teach students to expand their thinking to be outside of linear thinking and right or wrong answers. We wanted to develop an environment would teach students how to deal with chaos and uncertainty and to see new opportunities that come from a changing world. (Clouse, R. W. 2007,). While University curricula is changing, many University curricula teaches structure, order, linear thinking and certainty, while the world is filled with chaos ambiguity and uncertainty. This project provided the student with an opportunity to begin with an idea, create a product and to commercialize the product utilizing a multidisciplinary innovative problembased learning approach. Clouse, R. W., Aniello, J., Burkemper, A. \& Peters, S. 2018).

We believe that there is a need for paradigm change in college universities across the United States and perhaps the world at large. This project demonstrated that a multidisciplinary approach to learning can greatly improve the learning rate and enhance learning environments within University structures.

This project was funded in part funds from the Kentucky Science and Technology program and by funds from The Clouse Elrod Foundation, Incorporated. 


\section{REFERENCES}

Bilen, S. G., Kisenwether, E. C., Rzasa, S. E. \& Wise, J. C. (2005). Developing and accessing students' entrepreneurial skills and mind-set. Journal of Engineering Education.

Clouse, R. W. (1994). Education: a paradigm shift presentation, IBM Marketing Executive Program, Atlanta, GA.

Clouse, R. W., Goodin, T. L. (2001a). Creating an entrepreneurial culture: breaking the disciplinary boundaries, Proceedings of the 2001 American Society for Engineering Education Annual Conference \& Exposition: American Society of Engineering Education.

Clouse, R. W., \& Goodin, T.L. (2001b). Entrepreneurs in action: A case-based model. Proceedings of the Academic of Free Enterprise Education 5(1).

Clouse, R. W. Aniello, J., Biernacki, J. (2003). Entrepreneurs in action!:A problem-based learning environment for engineering entrepreneurship. Proceedings of the American Engineering Society.

Clouse, R. W. (2007, June). Learning in Action!: A problem- based learning environment for developing the entrepreneurial spirit: Entrepreneurial Leadership and Non-Traditional Ways to Enhance Students in Entrepreneurship and Innovation. Proceedings of the National Conference of the American Society for Engineering Education. Honolulu, HI.

Clouse, R. W., Goodin, T. L. (2008). Entrepreneurs in Action: case manual and entrepreneurship cases. The Forum for Entrepreneurship Education. Vanderbilt University.

Clouse, R. W., Goodin, T., Aniello, J. S., Roberts, J. \& Stowe, C., (2011). Building cross disciplinary entrepreneurship/innovation programs across multiple universities: A Coleman Model.

Proceedings of the 2011 Annual Conference of the United States Association of Small Business and Entrepreneurship. Hilton Head, SC. January 2011.

Clouse, R. W. (2013). Learning In Action: A commercialization process model, Atlantic Marketing Association Conference Proposal. Atlantic Marketing Association.

Clouse, R. W., Goodin, T., Aniello, J. (2016) Entrepreneurs in Action! An authentic learning experience. In Morris and Liguori (Eds.). Annuals of Entrepreneurship Education and Pedagogy - 2016. Massachusetts: Edward Elgar Publishing.

Clouse, R. Wilburn, Aniello, Joseph, Burkemper, Andy \& Peters, Susan. (2018). From here to eternity--what is next for entrepreneurship pograms? USASBE Conference Proposal Presentation.

Creed, C. J., Suuberg, E. M. \& Crawford, G. P. (2002). Engineering entrepreneurship: An example of a paradigm shift in engineering education. Journal of Engineering Education.

Murphy, R.,Tadokoro, S., Nardi, D., Jacoff, A., Fiorini, P., \& Erkmen. A., (2008). "Rescue Robotics," Handbook of Robotics (B. Sciliano and O. Khatib, eds.), pp. 1151-1174, Springer-Verlag,

Murphy, R., Steimle, E., Hall, M., Lindemuth, M.,Trejo, D., Hurlebaus, S., Medina-Cetina, Z., \& Slocum, D. (2009). "Robot-assisted bridge inspection after hurricane Ike”, IEEE International Workshop on Safety \& Rescue Robotics, 2009.

Skladany, M., Clausen, R., Belton, B. (2007) "Offshore aquaculture: the frontier of redefining oceanic property". Society and Natural Resources, 20: 169-176. 